\title{
THE RISKS AND REWARDS OF COMPUTING EVERYWHERE FOR SMALL BUSINESS ENTREPRENEURS
}

\author{
Richard A. Bassett, Southern Connecticut State University, bassettr3@southernct.edu \\ Anthony S. Richardson, Southern Connecticut State University, richardsona4@southernct.edu \\ Robert A. Page, Southern Connecticut State University, pager1@southernct.edu
}

\begin{abstract}
Gartner Inc. has identified Computing Everywhere as the top strategic technology trend of 2015. Computing Everywhere affords Small Business Entrepreneurs the ability to leverage investments in mature convergent technologies by rapidly deploying extended user access to important business data and information via mobile devices across a vast array of platforms from virtually any Internet enabled location at any time for reduced costs. Entrepreneurs in the small business space are especially well positioned to exploit the promise of this newest trend due to the low cost of entry, the widespread ownership of mobile devices by their stakeholders, and the plentiful availability of low cost high-speed bandwidth and the perception of low risk.
\end{abstract}

Keywords: Computing Everywhere, Information Security, Small Business Entrepreneurs, Risk, Rewards, Cloud Computing

\section{INTRODUCTION}

As Cloud computing continues to mature, becoming more pervasive, it has attracted significant investments from large companies such as Microsoft, SAP, Oracle, Salesforce.com, Intuit, Amazon, Dell, AT\&T and Verizon [27] which have a plethora of subscription based business applications brought to market that can be accessed at acceptable performance levels via rented bandwidth, data centers and communication platforms with promises of unlimited information access anywhere, anytime. Small businesses in particular are interested in using web-enabled technologies across the Cloud to minimize expenditures on their own IT infrastructure, such as the costs of servers.

Today, business owners can essentially outsource everything from their accounting systems and unified messaging systems to their digital storage space and office software programs. The results are not only smaller start-up costs, because the businesses can subscribe to all those services instead of buying them up front, but also a set of services that can be accessed from anywhere with a connection to the Web [11].

However, research and user feedback is emerging that challenges these claims with hidden long-term costs and complications. This paper reviews relevant literature and empirical studies on this topic to explore the limitation of the Cloud and Computing Everywhere to Small Business Entrepreneurs. Levels of adoption vary depending upon two strategic contingencies: the need for security versus accessibility, and reliability versus flexibility. Implications will be discussed.

\section{THE EVOLUTION OF CLOUD COMPUTING}

Basically, cloud computing refers to any form of web-based, shared computing service [11] More specifically, the cloud includes any internet-delivered, subscription-based or pay-per-use service applications that enhance IT capabilities as well as the hardware and systems software required to run them $[2,22]$.

The National Institute of Science and Technology concludes: Cloud computing is a model for enabling ubiquitous, convenient, on-demand network access to a shared pool of configurable computing resources (e.g., networks, servers, storage, applications, and services) that can be rapidly provisioned and released with minimal management effort or service provider interaction $[12,29]$.

Cloud computing began when internet applications and storage capacity allowed service providers to duplicate functions previously reserved for dedicated mainframes, such as memory backup and storage. Managed service 
providers took the next step, offering service applications to IT departments instead of end-users [22]. Now cloud computing can range from simple utility computing, such as storage and backup through the comprehensive integration of multiple services in multiple organizations [12].

\section{Cloud Trends}

Customer demand has dramatically increased and service providers have multiplied; now including industry leaders like Microsoft and Google. IHC Technologies forecast that by 2015, business revenues from utilizing the cloud might exceed one trillion dollars a year, making it the fastest growing sector in the technology industry [8, 11, 12]. There has been an explosion of investment in cloud service vendors; Amazon dominates this market, with stiff competition from IBM, Apple, Cisco, Google, Microsoft, Salesforce.com and many others [27]. Cloud-based sales revenue streams have followed: By 2015, end-user spending on cloud services could be more than $\$ 180$ billion. [44] Cloud-related tech spending by businesses is forecast to triple from 2011 to 2017 according to IHS Technology. By 2017 , enterprise spending on cloud computing will amount to a projected \$235.1B, triple the \$78.2B spent in 2011 according to the research firm's analysis [8]. In 2017, global business spending for infrastructure and services related to the cloud will reach an estimated $\$ 174.2 \mathrm{~B}$, up $20 \%$ from the amount spent in 2013 according to IHS Technology [8]. It is predicted that the global market for cloud equipment will reach $\$ 79.1$ billion by 2018 [44].

United States firms have spent more than $\$ 13$ billion on cloud computing services by the end of 2014 [44]. This industry continues to expand, and shows no signs of weakness. From 2012 to 2017 global data center traffic is forecasted to triple from 2.6 to 7.7 zettabytes annually - a 25 percent compound annual growth rate - while overall global cloud traffic is forecasted to quadruple - a $35 \%$ increase [44]. Further from 2013 to 2018, Cloud applications are projected to increase from 82 to $90 \%$ of total mobile data [7].

\section{THE EVOLUTION OF MOBILE COMPUTING FOR BUSINESSES}

The change in the portability of computing devices has evolved rapidly over the past 25 years with these changes presenting significant disruptions for small businesses with respect to the ways that they leverage today's mobile technology.

Mobile Computing is taking a computer and all necessary files and software out into the field [20]. There are several different dimensions under which mobile computers can be defined: (1) in terms of physical dimensions; (2) in terms of how devices may be hosted; (3) in terms of when the mobility occurs; (4) in terms of how devices are networked; (4) in terms of the type of computing that is performed [33].

In the early 1990's, users and small businesses were limited to computer portability, which entailed bulky devices that were difficult to carry from point-to-point for performing analysis and operational work. These devices were not Internet connected, which meant that all work performed locally on a given device was usually transferred via floppy drive. Today, most laptops (mobile PCs) have inbuilt wireless capabilities and can connect to Internet using wireless technology called Wi-Fi (wireless fidelity). While on the road, they can locate public Wi-Fi "hotspots" and easily connect to company intranet and access important information [45].

Mobile phones have become the main tool for managing the complex choreography of everyday life. Globally, cell phone subscribers now outnumber landline phone subscribers, and more than 210 million Americans have mobile phones. In addition to its role in voice communications, the cell phone is increasingly the Internet access device of choice. Wireless mobile phone Internet access is widely available in the United States, and coverage is rapidly expanding. The increasing computing power of mobile phones and devices, coupled with the widespread availability of high-speed wireless networks, will change the way mobile devices are used, expanding their role from a communications tool to a key operational device [21].

Personal Digital Assistants (PDA's) are handheld computing device with a larger screen and many more advanced applications than most cell phones, and may or may not provide phone capability [44]. The original PDA was built to mobilize contacts, calendars and notes. They replaced bulky paper organizers and seamlessly synced to PC productivity software like Outlook. It was a compelling product in the US where small business customers needed to keep track of hundreds of contacts. Users could even 'beam' contacts to each other via infrared [10]. 
A Smartphone is basically a cell phone and PDA combined. Smartphones have advanced capabilities and PC-like functionality such as Internet access, e-mail, faxing, and remote data transfers. Smartphones often come with a preinstalled operating system, such as the Windows Mobile, RIM BlackBerry, and the iPhone [45]. Today's cell phones have personal computer functionality — providing music and video entertainment, games, Internet browsing, and business and personal productivity applications. Smart phones connected to increasingly available wireless Internet data access services provide a small but powerful mobile office capability [21]. The benefits of using smartphones simply translate into greater confidence and optimism regarding future revenue growth of small businesses. Small businesses that use smartphones are more likely to believe that they will experience revenue growth compared to those that do not use smartphones. Small businesses that use smartphones are also more likely to say that their businesses are more profitable than those that do not currently use smartphones [34].

A Tablet is a general-purpose computer contained in a touchscreen panel. Although earlier tablet computers required a stylus, fingers operate modern tablets, and a stylus is an option [31]. Tablet use by businesses jumped significantly around 2010, as businesses have started to use them for conferences, events and trade shows. In 2012, Intel reported that their tablet program improved productivity for about 19,000 of their employees by an average of 57 minutes a day [38].

Wearable Devices: Wearable computers, also known as body-borne computers or wearables are miniature electronic devices that are worn by the bearer under, with, or on top of clothing [25]. According to a Vanson Bourne survey of 300 IT decision makers in the UK, 29 per cent of UK businesses have some form of wearable technologies projects in practice. The main reasons for such projects are employee well being (16 per cent), instant access to important information (15 per cent), and improved customer service (14 per cent) [36].

\section{THE EVOLUTION OF BUSINESS APPLICATIONS}

Until about 2005, most small businesses typically ran business application software that were stored locally on their laptop computers, desktop computers or servers. In multi-user network environments this was a distributed Clientserver computing [24] approach that generally required both a server component of the application, which usually functioned as the host and data storage container, and a client component, which consisted of software installed on each of the user's workstations for running application components locally. In single-user environments stand-alone applications and corresponding data were stored on the local hard drive of the users station.

Installations of client-only and Client-server software are time consuming, difficult, often error prone and expensive as the available system resources and the operating system versions on all of the computer systems hosting and running the application software must be configured in perfect unison [6]. Servers and workstations with insufficient resources or out of date operating systems must often be upgraded or replaced to accommodate a new application software package. It's not uncommon for installations of typical multi-user accounting or ERP software to take days or weeks to get running properly.

Updates and upgrades to the application software were often deferred or skipped entirely by small business entrepreneurs due to the challenges of time, cost and complexity involved in their installation, plus the added risks to upgrading an operational application system included expensive downtime and potential for significant data loss.

As Internet bandwidth became more affordable and early web-enabled application companies such as NetSuite and SalesForce.com [35] enjoyed commercial success by early adopters in the subscription-based Cloud computing market, other technology companies noticed and started to invest in their web-enabled application services.

The proliferation of powerful, easy to use mobile tablets and smartphones provided a venue for small footprint applications (APPS), which initially did not provide very much in the way of business value, but evolved over time. As more and more users adopted these mobile devices, the demand for higher quality APPS grew. Many technology companies recognized the opportunity in this 'small footprint' space and rose to the challenge by developing useful applications for their business customers [38]. 
Cloud-based subscription service companies quickly learned that one of the best ways to retain clients was to continue to build on the value proposition, so they started extending access to their web-based system by building on and improving their smart APPS for mobile devices [23].

Over the past 10 years, small business software deployment has moved from being large footprint resource dependent applications locally installed on the hard drives of servers and workstations to small footprint scripts which run in web-browsers on workstations and APPS on mobile devices. It is now possible to run many business applications on entirely web-enabled solutions without the need to locally store application software.

\section{THE POTENTIAL OF COMPUTING EVERYWHERE FOR SMALL BUSINESS}

Small business owners tend to rate improved efficiency and IT cost reduction as the most important benefits offered by web-based computing. At the simplest level, cloud computing offers convenient, affordable services such as file sharing and storage to appeal to small businesses [12, 27]. Computing Everywhere enhances that potential by increasing access and portability of these advantages:

\section{Comprehensive}

\begin{tabular}{|c|c|c|}
\hline Efficiency & $\begin{array}{l}\text { Affordable Access } \\
\text { (e.g. computer analytics, } \\
\text { scalability, etc. ) }\end{array}$ & $\begin{array}{l}\text { Increased Performance } \\
\text { (e.g. more productivity, } \\
\text { collaboration, etc.) }\end{array}$ \\
\hline & $\begin{array}{l}\text { Cost Control } \\
\text { (e.g. less power, hardware, } \\
\text { storage expenses, etc.) }\end{array}$ & $\begin{array}{l}\text { Niche Performance } \\
\text { (e.g. hybrid clouds, } \\
\text { custom services) }\end{array}$ \\
\hline
\end{tabular}

Figure 1. Computing Everywhere Strategic Advantages

\section{Cost Control - Quicker Startup with fewer Costs}

Small business can minimize hardware and software purchases and redundancies through the cloud without compromising effectiveness $[9,12,26]$. Cloud computing services are typically pay as you go, so there's no need for capital expenditure at all. The short-term contracts (in some cases by the hour or day) for IT services such as processing and storage, allowing businesses to reduce costs during spikes of unusually low or high low demand without compromising future capacity [18,28]. Cloud computing also minimizes power consumption costs [4], allowing start-ups to generate additional customer goodwill as a socially responsible "green" business. [39]

Cloud computing services provide companies the benefits of having numerous servers with none of the hassle. Keeping servers up and running smoothly is left to the service providers. If this responsibility is left to a single IT technician who does not work $24 \times 7$, the solution may not be as reliable. This allows start-ups to reduce the size of the IT budget after cloud adoption $[8,44]$. A recent survey found that $14 \%$ of small business cloud adopters saw a $20 \%$ or more IT expense reduction versus non-cloud users who only reported a $3 \%$ reduction [40].

\section{Affordable Access - Flexible Scale and Analytics}

The second a company needs more bandwidth than usual; a cloud-based service can instantly meet the demand because of the vast capacity of the service's remote servers. In fact, this flexibility is so crucial that $65 \%$ of respondents to an InformationWeek survey said "the ability to quickly meet business demands" was an important reason to move to cloud computing [35]. And because cloud computing is much faster to deploy, businesses have minimal project start-up costs and predictable ongoing operating expenses [35]. 
Cloud computing provides the connectivity and software capabilities necessary to access, manage and analyze massive amounts of data in relatively short periods of time. The cloud makes real-time access of a wide variety of data sources relatively convenient, and provides the analysis software necessary to improve the quality of information for managerial decision making through unifying enterprise data with market trends and emerging customer preferences and mining that information. This improves and targets marketing efforts (such as tracking customer preferences), customer engagement and service, and the control over operations. [9, 18, 26, 27, 28].

Beyond tracking customer preferences, the advent of ubiquitous computing also provides opportunities to small and midsized businesses to experience "effortless utility" through use of ambient informatics. Ambient informatics is a state in which information is freely available at the point in space and time someone requires it, generally to support a specific decision - accessible when, how and where the user [prefers] it [17].

\section{Increased Performance and Niche Markets}

Beyond cost lies differentiation, where companies distinguish themselves from their rivals through some competitive advantage, such as brand, performance, quality, niche customization, etc. [32]. Computing Everywhere will help small business entrepreneurs compete on a more level playing field with their larger competitors by giving them the opportunity to capitalize on the benefits that scalable ubiquitous web-based computing has to offer - a sustainable competitive advantage [12].

Increasing productivity is often attributed to migrating various functions to the cloud, primarily due to increases in speed and capacity. However, the level of communication, collaboration and real-time analysis actually increase. Collaboration and communication increase in speed and frequency both within the organization and between the organization and its partners, ranging from consumers to other stakeholders, such as suppliers and consumers, regardless of where they are located or what technologies they are [1, 18, 26, 27, 28]. Linking corporate clouds with social networks not only opens a dialogue with customers, it can attract and retain them. In 2013 64\% of CIO's IBM interviewed rated cloud computing as a crucial technology for customer engagement; and $67 \%$ were actively looking into how cloud technologies can better serve and collaborate with customers $[8,9]$.

In turn, this improved flow of information drives innovation, and improves speed and flexibility in forming strategic alliances, joint ventures and mergers and acquisitions [39]. Prior to the cloud, this level of strategic response was unaffordable and reserved for only the largest and most well financed organizations. This allows small business to rapidly adapt to changing industry conditions and emerging market trends, and to reduce the time needed for new product/service development cycles [1, 9, 18, 26, 27, 28].

Project management tools are becoming part of the cloud revolution, with an array of specialist firms offering project management cloud computing toolkits. Sophisticated program management (PPM) perspective-centric organizations have complex, mature project and program tools, containing the standard software methodologies, and approaches necessary to initiate projects/programs per organizational standards. Storing these toolkits in the cloud makes them accessible and updatable in real-time by all project/program managers. For those managers at remote locations, the time and cost associated with project start-up could dramatically reduce, with access to best-practice methodologies and prior experience enabling progression of the project from mandate to initiation swifter than ever before. Cloud enables the standardization and continual improvement of the PPM toolkit to occur centrally, such as within an enterprise PMO. Organizations could build customized cloud applications, replacing today's IT project management tools with organization-specific PPM software applications that are accessed through a browser. Updates and additions to the PPM toolkit could be immediately rolled-out to all project teams. Enhanced functionality may be made available across all geographies, and to any internet-enabled device; making a tablet PC equally as useful as a laptop. This creates opportunities for smaller organizations that historically may have been unable to capitalize on the use of sophisticated PPM tools that were the preserve of large firms with mature project management functions [30]. 


\section{THE RISKS OF COMPUTING EVERWHERE FOR SMALL BUSINESSES}

There are numerous risks with large potential downsides associated with Computing Everywhere for small business entrepreneurs. Mitigating these risks requires entrepreneurs to spend considerable time strategically planning the alignment of business processes with the their potential technology rather than jumping quickly to deployment.

\section{Cost Control or Accretion - True Costs of Ownership}

The onramp to subscription-based web-services can appear to be very low cost at the onset, especially when very few users are consuming rather limited resources and services. A large part of the cost savings attraction for small business entrepreneurs is being able to bypass the costs of expensive internal servers, communication equipment, and the associated personnel cost. Web-based solutions shift the costs and physical needs of server-cooling systems, bandwidth, fire-suppression systems, backup generators, security systems and patrols, and staffing for 24/7 network operations centers onto the service providers giving the false impression that those costs have disappeared when in reality they are bundled into the ongoing subscription fee [3].

Subscription-based web-solution companies base their subscription fees on varying, complex pricing plans for different applications and scalable variables such as number of users, data throughput, data storage, service level agreements, backup/retention plans, and sometimes business metrics [16, 41, 42].

Cost savings is one of the largest perceived benefits of using web-based solutions, but the true Total Cost of Ownership (TCO) can be masked by the attraction of shorter-term cost advantages over the longer-term.

\section{Security Issues}

Information security remains a major challenge in all avenues of computing as sophisticated hackers continue to exploit weaknesses in systems and search for flaws in internal business controls [11,12, 19, 42]. The small business sector is especially vulnerable to information security risks due to the lack of internal information security controls inherent in entrepreneurial enterprises as businesses in this sector are typically very fast moving, make quick 'gut based' decisions driven by finance, opportunity and even day-to-day survival, often while working with a semiskilled workforce. Leveraging web-based applications can improve security for small businesses, especially if the application service providers continuously invest in information security [11, 12, 19, 42].

\section{Vendor Lock-in}

Making the leap to any business software solution is a big decision that can severely limit future selection options as the ability to switch application vendors and move to competitive solutions diminishes in direct proportion to the amount of time that a business uses a proprietary solution. Once users are trained, systems are configured, databases are built, and the solution is operational on a day-to-day basis, it becomes incredibly difficult and costly to switch to another solution regardless of the level of dissatisfaction the clients may be experiencing with their vendor [5].

\section{Scaling Issues}

Smartly choosing web-based applications which have the ability to scale in tandem with business growth is important as some solution providers do not offer the opportunity to scale (grow) past a certain point. Other solution providers move their clients into an entirely different type of solution when they hit the limit of the 'starter' service.

\section{Lost Devices}

Mobile devices are frequently lost, misplaced or stolen. The risks and potential costs associated with lost devices can far exceed their contractual replacement costs, as many such devices are not properly protected with passwords, encryption, or remote wiping capabilities. While users of most mobile devices tend to store minimal data on their devices, they often store authentication credentials such as usernames and passwords within their applications while leaving their email account and text messaging accounts wide open. When an unsecured, unlocked smartphone falls into someone else's hands with stored authentication credentials and open email/text access it becomes extremely 
easy for an identity thief to impersonate the legitimate user and potentially steal business trade secrets, obtain unauthorized access to bank accounts, and delete or destroy critical company data [13].

\section{Unplanned Upgrades}

Vendors of Cloud-based solutions often push their upgrades, patches and fixes out to their clients on their own timeframe without advanced notification. The implications are that the client-side user experience system may change radically overnight, for better or worse, as application updates which are loaded on to the vendors' servers are accessed via browsers on workstations or APPS on mobile devices the very next time they are accessed. Entrepreneurs historically have had the option of skipping updates in a traditional computing setting where software is installed on to equipment owned by the small business, but the option of deferring updates is not generally available in the cloud-based application world.

\section{Variable Performance Speeds}

Accessing data via cloud-based applications can yield variable performance speeds for a number of reasons. First, as the amount of data and the amount of distance it has to travel increases, speed of transmission tends to slow, giving local data storage real advantages over distant data centers. Secondly, "Cloud services have finite amounts of bandwidth to share among all users, so the more customers they have, the slower they operate." [3]. Finally, speed is constrained by the bandwidth capacity of the user's Internet connection. Large documents and web-based applications require significant bandwidth to download.

\section{Possible Downtime}

Web-based applications subject small business users on the reliability of their Internet connection as well as their service provider's capacities. When their Internet connection fails, or servers crash without adequate technologic redundancies, offline data can neither be uploaded nor downloaded, making the Cloud more of a detention center [1, $15]$.

"If local Internet service suffers from frequent outages or slow speeds cloud computing may not be suitable for your business. And even the most reliable cloud computing service providers suffer server outages now and again" [3, 12, $14,42]$.

\section{Support Concerns}

In the software world, cloud-based service providers have earned the reputation for providing relatively poor service to their small business clients due to providing priority treatment for the largest enterprise clients, difficulty contacting support personnel via telephone or by e-mail, forcing customers to rely on Frequently Asked Questions (FAQ) pages and online community support, lack of comprehensive user manuals, inflexible options locked into proprietary applications or formats, and arbitrary application of complex rules for account suspensions and/or closures $[3,14,15,42]$.

Anita Campbell writes, "Customer service for Web apps leaves a lot to be desired -- All too many cloud-based apps make it difficult to get customer service promptly - or at all. Sending an email and hoping for a response within 48 hours is not an acceptable way for most of us to run a business" [42].

\section{IMPLICATIONS}

Computing Everywhere has come into laser-like focus recently by being identified by Gartner as the top technology trend for 2015 [37]. The roots of Computing Everywhere can be traced back to 1988 and a term known as ubiquitous computing that was coined by Mark Weiser, the former Chief Technologist of Xerox at the time. Mark Weiser noted "Ubiquitous Computing can occur using any device, in any location, and in any format" [43]. 
A significant technological shift in the way that business applications have been deployed, locally stored Clientserver verses Cloud-based, has occurred over the past 10 years as web-enabled hardware and software has become more pervasive, more robust, easier to user and less costly. The shift from most business applications being only internally hosted Client-server based to being web-based provides tremendous flexibility for the businesses that embrace Computing Everywhere. Computing Everywhere is a tremendous market equalizer in that it can help small business entrepreneurs to level the business playing field with their competitors by affording them access to the same world-class web-based technological solutions, which are available to the top companies within their business sectors.

However, Computing Everywhere clearly poses different levels of risk for different types of small businesses

\section{REFERENCES}

1. Aljabre, A. (2012). Cloud computing for increased business value. International Journal of Business and Social Science, 3(1), 234-239.

2. Armbrust, M., Fox, A., Griffith, R., Joseph, A.D., Katz, R., Konwinski, A., Lee,G., Patterson, D., Rabkin, A., Stoica,I. \& Zaharia, M. 2009. Above the Clouds: A View of Cloud Computing. UC Berkeley Reliable Adaptive Distributed Systems Laboratory White Paper. Retrieved from http://radlab.cs.berkeley.edu/

3. Belicove, Mikal E. (Sep 17, 2013) The Downsides to Cloud Storage. Entrepreneur. Retrieved May 13, 2015, from http://www.entrepreneur.com/article/227373

4. Beloglazov, A., Abawajy, J., \& Buyya, R. (2012). Energy-aware resource allocation heuristics for efficient management of data centers for cloud computing. Future Generation Computer Systems, 28(5), 755-768.

5. Bosari, J. (2012). Real Costs of Choosing the Wrong Software Retrieved from Vendor.http://www.forbes.com/sites/moneywisewomen/2012/10/04/real-costs-of-choosing-the-wrong-softwarevendor/

6. Charette, R. (2005). Why Software Fails. Retrieved from http://spectrum.ieee.org/computing/software/whysoftware-fails

7. Cisco 2014. Cisco Visual Networking Index: Global Mobile Data Traffic Forecast Update, 2013Đ2018. Retrieved from http://www.cisco.com/c/en/us/solutions/collateral/service-provider/visual-networking-indexvni/white_paper_c11-520862.html

8. Columbus, L. Mar 14, 2014 Roundup Of Cloud Computing Forecasts And Market Estimates, 2014 Forbes Retrieved from: http://www.forbes.com/sites/louiscolumbus/2014/03/14/roundup-of-cloud-computingforecasts-and-market-estimates-2014/

9. Comfort J., Hayman, C. \& Hupfer, S. 2013 Under cloud cover: How leaders are accelerating competitive differentiation. Armonk, NY: IBM Center for Applied Insights.

10. Dediu, H. (2010, December 27). Retrieved May 13, 2015, from The parable of the PDA: predicting the smartphone's future: http://www.asymco.com/2010/12/27/the-parable-of-the-the-pda-predicting-thesmartphones-future/

11. El Akkad, Omar (2010, Nov. 11). Outsource IT headaches to the cloud. The Globe and Mail. http://www.theglobeandmail.com/report-on-business/small-business/sb-digital/web-strategy/outsource-itheadaches-to-the-cloud/article1318511/

12. Erl, T., Puttini, R., \& Mahmood, Z. (2013). Cloud Computing: Concepts, Technology, \& Architecture. Pearson Education.

13. Ernest \& Young. September 2013. Bring your own device, security risk considerations for your mobile device program. Retrieved May 13, 2015, from http://www.ey.com/Publication/vwLUAssets/EY_-

Bring_your_own_device:_mobile_security_and_risk/\$FILE/Bring_your_own_device.pdf

14. Freedmansept, David H.. (2011, Sep. 22) Thinking About Moving to the Cloud? There Are Trade-Offs. Retrieved from http://www.nytimes.com/2011/09/22/business/smallbusiness/what-to-consider-when-thinkingabout-moving-to-the-cloud.html

15. Ganorem Pravin. (Feb 25 2014). Drawbacks of Cloud Computing. Retrieved from https://www.ibm.com/developerworks/community/blogs/84f27519-a96d-4066-bb15-

5178a84a85cb/entry/drawbacks_of_cloud_computing?lang=en 
16. Gartner Pressroom. (2009). Gartner Fact Checks the Five Most-Common SaaS Assumptions. Retrieved from http://www.gartner.com/newsroom/id/889713

17. Greenfield, A. (2006). Everyware: The Dawning Age of Ubiquitous Computing. In A. Greenfield, Everyware: The Dawning Age of Ubiquitous Computing (pp. 23-24).

18. Iyer, B., \& Henderson, J. C. (2012). Business value from clouds: learning from users. MIS Quarterly Executive, 11(1), 51-60.

19. Kalloniatis, C., Mouratidis, H., \& Islam, S. (2013). Evaluating cloud deployment scenarios based on security and privacy requirements.ÊRequirements Engineering,Ê18(4), 299-319.

20. Kamal, R. (2011). Mobile Computing. 2nd ed. Oxford Higher Education/Oxford University Press.

21. King \&Townsend (2007) Retrieved from http://httpdownload.intuit.com/http.intuit/CMO/intuit/futureofsmallbusiness/SR-1037B_intuit_tech_trends.pdf Intuit.

22. Knorr, E., Gammen, G. (2014). What cloud computing really means. InfoWorld, Retrieved from: $\mathrm{http} / / / \mathrm{www}$.infoworld.com/d/cloud-computing/what-cloud-computing-really-means-031?page $=0,0$

23. Lenati, LLC. (2013, May 15). 5 Go-To-Market Challenges to Consider before Unveiling Cloud Services. (Web Blog). Retrieved from http://www.lenati.com/2013/05/5-go-market-challenges-consider-unveiling-cloudservices/

24. Maffeis, S. (2003). Client-server computing. In Encyclopedia of Computer Science, $\left(4^{\text {th }}\right.$ ed., pp 215-218)

25. Mann, S. (2014). Wearable Computing. In "The Encyclopedia of Human-Computer Interaction, 2nd Ed.". Aarhus, Denmark: The Interaction Design Foundation.

26. McAfee, A. (2011). What every CEO needs to know about the cloud. Harvard Business Review, 89(11), 124132.

27. McCue, TJ (2014, Jan. 29). Cloud Computing: United States Businesses Will Spend $\$ 13$ Billion On It. Forbes . http://www.forbes.com/sites/tjmccue/2014/01/29/cloud-computing-united-states-businesses-will-spend-13billion-on-it/

28. McKendrick, J. (2012, Feb. 2). 6 Shining Examples of Cloud Computing in Action. Forbes. Retrieved from: http://www.forbes.com/sites/joemckendrick/2012/02/22/6-shining-examples-of-cloud-computing-in-action/

29. Mell, P., \& Grance, T. (2011). The NIST definition of cloud computing. NIST Special Publication 800-145 (Gaithersburg, MD: National Institute of Standards and Technology).

30. Moorhouse Consulting. (2011). Cloud Computing and Project Management. Retrieved May 13, 2015, from $\mathrm{http} / / / \mathrm{www} . \mathrm{moorhouseconsulting.com/news-and-views/publications-and-articles/cloud-computing-and-project-}$ management

31. PC MAG. (2015). Retrieved May 13, 2015, from PC MAG Encyclopedia: http://www.pcmag.com/encyclopedia/term/52520/tablet-computer

32. Porter, M. (1980). Competitive Strategy - Techniques for Analyzing Industries and Competitors.New York, NY. The Free Press.

33. Poslad, S. (2009). Ubiquitous Computing Smart Devices, Smart Environments and Smart Interaction. In S. Poslad, Ubiquitous Computing Smart Devices, Smart Environments and Smart Interaction (pp. pp. 115Đ133). Wiley.

34. Rogers, C. and Scheer, M. (2008). http://www.blackberry.com/. Retrieved May 13, 2015, from http://www.blackberry.com/framed/sprint/assets/docs/BWRS_RIM_Article1_Smartphones_Payoff_V2_PDF.pd $\mathrm{f}$

35. Salesforce.com. (2015). Why Move to the Cloud? 10 Benefits of Cloud Computing. Retrieved from $\mathrm{http} / /$ www.salesforce.com/uk/socialsuccess/cloud-computing/why-move-to-cloud-10-benefits-cloudcomputing.jsp

36. Schutte, S. (2014, May 1). Retrieved May 12, 2015, from http://realbusiness.co.uk/: http://realbusiness.co.uk/article/26554-wearable-technologies-can-boost-employee-productivity

37. Spender, A. 2015 Gartner's Top 10 Strategic Technology Trends for 2015, http://www.gartner.com/smarterwithgartner/gartners-top-10-strategic-technology-trends-for-2015/

38. Stevenson, K. (2012). Intel IT Performance Report. Retrieved May 13, 2015, from http://www.intel.com/content/dam/www/public/us/en/documents/reports/2012-2013-intel-it-performancereport.pdf. Intel.

39. Tarrant, Stuart 2014, Jan. 29. 5 Unexpected Benefits of Cloud Computing. Codestone News. Retrieved from: http://blog.codestone.net/5-unexpected-benefits-of-cloud-computing 
40. TrendMicro. (2012 November 13). 5 Cloud Computing Myths Every Small Business Should Know About. Retrieved May 13, 2015, from http://blog.trendmicro.com/5-cloud-computing-myths-and-truths-for-smallbusinesses/

41. Walterbusch, M., Martens, B., \& Teuteberg, F. (2013). Evaluating cloud computing services from a total cost of ownership perspective. Management Research Review,36(6), 613-638.

42. Ward, S. (2015) 5 Disadvantages of Cloud Computing Consider These Before You Put Your Small Business In the Cloud. Retrieved May 13, 2015, from http://sbinfocanada.about.com/od/itmanagement/a/Cloud-ComputingDisadvantages.htm

43. Weiser, M. (1993 June). Some Computer Science Problems in Ubiquitous Computing, Communications of the ACM. (reprinted as "Ubiquitous Computing". Nikkei Electronics; December 6, 1993; pp. 137-143.)

44. Woods, J. (2014). 20 Cloud Computing Stats Every CIO Should Know. Silicon Angle. retrieved from http://siliconangle.com/blog/2014/01/27/20-cloud-computing-statistics-tc0114/

45. Worksmart. (2008). Small Business Mobility: Enabling your team to work anywhere, anytime. Retrieved May 13, 2015, from http:/www.worksmart.com/files/whitepaper/worksmart_sb_mobility_3.pdf 